\title{
Lipid Profile of Coronary Heart Disease Patients: A Prospective Observational Study
}

\author{
Md. Rezaul Alam ${ }^{*}$, Md. Bashir Uddin², Md. Mojib Uddin³, Mahbubur Rahman ${ }^{4}$, Sougata Mitra ${ }^{5}$ \\ ${ }^{1}$ Department of Cardiology, M. Abdur Rahim Medical College, Dinajpur, Bangladesh \\ ${ }^{2}$ Department of Cardiology, Kushtia Medical College, Kushtia, Bangladesh \\ ${ }^{3}$ Department of Pharmacology, Rajshahi Medical College, Rajshahi, Bangladesh \\ ${ }^{4}$ Department of Cardiology, Rangpur Medical College \& Hospital, Rangpur, Bangladesh \\ ${ }^{5}$ Department of Pharmacology and Therapeutics, Pabna Medical College, Pabna, Bangladesh \\ Email: ^reezaul74@gmail.com
}

How to cite this paper: Alam, Md.R., Uddin, Md.B., Uddin, Md.M., Rahman, M. and Mitra, S. (2021) Lipid Profile of Coronary Heart Disease Patients: A Prospective Observational Study. World Journal of Cardiovascular Surgery, 11, 114-124. https://doi.org/10.4236/wjcs.2021.1111015

Received: June 7, 2021

Accepted: November 27, 2021

Published: November 30, 2021

Copyright $\odot 2021$ by author(s) and Scientific Research Publishing Inc. This work is licensed under the Creative Commons Attribution International License (CC BY 4.0).

http://creativecommons.org/licenses/by/4.0/ (c) (i) Open Access

\begin{abstract}
Background: Coronary heart disease (CHD) remains the major cause of mortality and morbidity in the entire world population despite therapeutic advances that control many risk factors. Lipid profile is regarded as an important factor in the development of coronary heart disease. There have been numerous studies confirming the association of hyperlipidemias with coronary heart disease in most of the Western as well as Asian countries of the world. But we have very little data on the relation between CHD and lipid profile. Aim of the Study: The aim of this study was to assess abnormal lipid levels and their association with coronary heart disease. Methods: This comparative observational study was conducted at the Department of Cardiology in M. Abdur Rahim Medical College, Dinajpur, Bangladesh from January 2019 to December 2019. Properly written consent was taken from all the participants before starting the main part of the investigation. Obeying inclusion and exclusion criteria of the study, a total of 131 participants were finalized as the study population. Among them, the Case Group was formed with 90 patients who had CHD, and with 41 healthy people, the Control Group was formed. All necessary data were collected, analyzed, and disseminated by several programs of MS-Office and SPSS version 23. Result: The study was conducted with 90 case group participants and 41 control group participants. Among the case group, $78 \%$ were male and $22 \%$ were female. Among the male case group participants, $44.29 \%$ were from 51 - 60 years of age, $35.71 \%$ were from 41 - 50 years of age and the rest $20 \%$ were above 60 years of age. On the other hand, among the female participants of Case Group, $45 \%$ were from 51 - 60 years of age, 30\% from 41 - 50 years of age, and 25\% were over 60 years of age. Regression analysis between the male and the female showed
\end{abstract}


the P-value of 0.242. Serum cholesterol concentration and HDL concentration were significant between the Case and Control groups in all age groups and the P-value was $<0.0001$ in every age group. Triglyceride concentration was significant between the Case and Control groups in $41-50$ and $51-60$ years age groups with a P-value of $<0.0001$. But in the $>60$ years age group, we did not find any significant correlation and there the P-value was 0.478 . LDL concentration between the groups showed significant correlations between the Case and Control groups in $41-50$ and 51 - 60-years' age groups where the $\mathrm{P}$ values were found, $<0.0001$ and 0.0002 respectively. But in the $>60$ years' age group, we did not find any significant correlation and there the Pvalue was 0.515 . Conclusion: In this study, it was found that the total cholesterol, triglycerides, HDL cholesterol, and LDL cholesterol concentrations were significantly higher in coronary heart disease (CHD) patients.

\section{Keywords}

Lipid Profile, Coronary Heart Disease, CHD, Cardiology

\section{Introduction}

Lipid profile means the pattern of lipids in the blood. It generally contains the level of total cholesterol (TC), triglycerides (TG), low-density lipoprotein (LDL), and high-density lipoprotein (HDL). In general, the lipid profile refers to a group of tests that are often done together to identify the risk of heart disease. These tests are used as potential indicators of whether someone is likely to have a heart attack or stroke caused by the blockage of blood vessels or hardening of the arteries. For a person of about $68 \mathrm{~kg}$, the typical total blood cholesterol synthesis is about $1 \mathrm{~g}(1000 \mathrm{mg})$ per day [1]. The increased levels of TC, TG, and LDL are found to be associated with a higher risk of coronary artery disease (CAD) and ischemic stroke [2]. On the other hand, population-based studies have consistently demonstrated an inverse association between HDL level with the risk of CAD [3]. Dyslipidemia is one of the primary causes of coronary artery disease (CHD). Elevated total cholesterol (TC), triglycerides (TG), low-density lipoprotein-cholesterol (LDL-C), and lowered high-density lipoprotein-cholesterol (HDL-C) are conventional risk factors in myocardial infarction patients [4]. According to the guidelines of the American Heart Association, the following values are prescribed for the above-mentioned risk factors for cardiovascular disease: total cholesterol: $<200 \mathrm{mg} / \mathrm{dL}$; triglycerides: $<200 \mathrm{mg} / \mathrm{dL}$; HDL: $>40 \mathrm{mg} / \mathrm{dL}$; and LDL: $<130 \mathrm{mg} / \mathrm{dL}$ [5]. A study by Adak found desirable TC level $(<200 \mathrm{mg} / \mathrm{dl})$ in $73.0 \%$, normal TG level $(<150 \mathrm{mg} / \mathrm{dl})$ in $59.0 \%$, optimal level of HDL-C $(<40$ $\mathrm{mg} / \mathrm{dl})$ in $82.0 \%$ and normal LDL-C $(<129 \mathrm{mg} / \mathrm{dl})$ in $32.0 \%$ of their study participants [3]. Nearly $16 \%$ of males and females had normal (40 - $60 \mathrm{mg} / \mathrm{dl}$ ) HDL-C respectively [4]. The previous study also found that a higher percentage of females (46.8\%) compared to the males (34.9\%) had an optimal level of LDL-C $(<100 \mathrm{mg} / \mathrm{dl})$. About $20.0 \%$ of males had a very high level of LDL-C $(>160 \mathrm{mg} / \mathrm{dl})$ 
while it was noted in only $6.7 \%$ of female patients [4]. LDL consists of more cholesterol than triglycerides and protein. Because it contains less lipid and more protein in comparison to VLDL, its density is greater. LDL is responsible for carrying cholesterol to cells that need it. The recent genetic analyses of a relatively common single nucleotide polymorphism (SNP) in the endothelial lipase gene and other SNPs associated with HDL cholesterol suggest that genetic mechanisms that raise plasma HDL do not decrease the risk of myocardial infarction [6]. In contrast, an earlier study of SNPs in the cholesteryl ester transfer protein (CETP) that impacts HDL levels indicated that SNPs associated with an increase in HDL corresponded with a lower risk of future myocardial infarction [7]. Some earlier clinical trials using agents that increase HDL showed that elevations in the lipoprotein can decrease the incidence of cardiovascular events [8]. On the other hand, VLDL particles mainly carry triglycerides, another type of fat, to your tissues. VLDL is similar to LDL cholesterol, but LDL mainly carries cholesterol to your tissues instead of triglycerides. In the human body, cholesterol is an essential component of cell membranes, which are the structures that border every cell [9]. Without cholesterol, T-cells (a type of white blood cell), for example, would not maintain their cell membranes, leading to rupturing of the cells. Cholesterol is also needed for the manufacture of steroid-based hormones, particularly sex hormones like testosterone and progesterone [10]. Other hormones that are produced mainly by the adrenal gland, also require cholesterol for production. Aldosterone is a hormone that makes the kidneys retain water, and Cortisol is a hormone that is important in suppressing inflammation in the body. These are two examples of hormones produced by the adrenal gland. Is also necessary for the skin to manufacture vitamin $\mathrm{D}$, which plays a vital role in how the body assists in maintaining bone density by using calcium [11]. Many previous studies on lipid profiles have been conducted in some of the famous institutions of Bangladesh. Among those institutions or hospitals, NICVD [12], Dhaka; ICDDR [13], Dhaka; BSMMU, Dhaka are some of the noticeable ones. Although there had been many studies conducted on the lipid profile of $\mathrm{CHD}$ patients in Bangladesh, there are some dissimilarities among the findings of those studies. Variations and dissimilarities are found even among several studies of the same institute or hospital. For this reason, we conducted this study to acquire some more specific information.

\section{Methods}

This comparative observational study was conducted at the Department of Cardiology in M. Abdur Rahim Medical College, Dinajpur, Bangladesh during the period from January 2019 to December 2019. Properly written consent was taken from all the participants before starting the main part of the investigation. The initial sample size was determined to be 200 participants, with 100 cases and 100 control patients. Due to time restraints, the inclusion and exclusion criteria of this study and the willingness of patients to participate in the study, a total of 131 participants were finalized as the study population. Among them, the Case 
Group was formed using 90 patients who had CHD, and the control group was formed with 41 healthy people. A convenient sampling method was used for the selection of the participants. The age of the participants was 41 years and above. All the demographic and risk factors related information were collected from the available patients records available in the hospital and by a data collection sheet provided to the participants, information about the patients. The patients of Case Group ( $\mathrm{n}=90)$ were selected with a history of angina or surviving myocardial infarction with or without DM and HTN, admitted and diagnosed in the coronary care unit of the mentioned hospital. According to the exclusion criteria of the study, CHD cases with liver impairment, renal disease, or thyroid disease were excluded. Clinically healthy subjects aged above 41 years who served as population-based controls were selected as the participants of the Control Group. Estimation of HDL-C and LDL-C was done through the phosphor-tungstic precipitation method. Estimation of Triglycerides (TG) was done by enzymatic colorimetric test. Serum of VHD patients were used for individual determinations of lipid profile for Cholesterol, HDL-C, LDL-C, and TG by using clinical laboratory kits. All necessary data were collected, analyzed, and disseminated by several programs of MS-Office and SPSS version 23.

\subsection{Inclusion Criteria}

- Case Group

$>$ Aged 41 years and above

Patients with history of angina or myocardial infarction

- Patients admitted at the coronary care unit of the study hospital

- Control Group

Aged 41 years and above

$>$ Willing to participate in the study

Clinically Healthy subjects

Willing to share necessary information

\subsection{Exclusion Criteria}

- Case Group

Less than 41 years of age

Patients with liver diseases, thyroid disease, or renal disease

Dentally Unstable

- Control Group

$>$ Less than 41 years of age

Mentally Unstable

Clinically Unhealthy

$>$ Unwilling to share necessary information

\section{Results}

In this study, among the total participants of the Case Group $(n=90)$ total of 70 
were male which was $78 \%$ and 20 were female which was $22 \%$. Among male participants of the Case Group 44.29\%, 35.71\%, and the rest 20\% were from $51-60$, 41 - 50, and $>60$ years' age group respectively. On the other hand, among the female participants of Case Group 45\%, 30\% and the rest 25\% were from 51 - 60, 41 - 50, and $>60$ years' age group respectively. In regression analysis between male and female participants of Case Group based on age, we found the P-value was 0.242 . So there had not been any significant correlation. In analyzing the age-wise distribution of serum cholesterol concentration between the groups we found, significant correlations between the Case and Control groups in all age groups and the $\mathrm{P}$-value was $<0.0001$ in every age group. On the other hand, in analyzing the age-wise distribution of triglyceride concentration between the groups we found, significant correlations between the Case and Control groups in 41 - 50 and 51 - 60 years age groups, and in both age groups the P-value was found to be $<0.0001$. But in the $>60$ years' age group we did not find any significant correlation and there the $\mathrm{P}$-value was 0.478 . In analyzing the age-wise distribution of HDL concentration between the groups we found, significant correlations between the Case and Control groups in all age groups and the P-value was $<0.0001$ in every age group. On the other hand, in analyzing the age-wise distribution of LDL concentration between the groups we found, significant correlations between the Case and Control groups in 41 - 50 and 51 - 60-years' age groups where the $\mathrm{P}$ values were found, $<0.0001$ and 0.0002 respectively. But in the $>60$ years' age group we did not find any significant correlation and there the P-value was 0.515 .

Among the total participants, the majority were male. Only $22.22 \%$ of the participants were female, and the male: female ratio was 7:2 (Figure 1).

Table 1 shows the age distribution of the participants of the case group, divided into 70 male and 20 female participants. The male and female percentage was almost similar in the age group of 51 - 60 years. In the age group of $41-50$ years, the male percentage was slightly higher than the female, with $35.71 \%$ male and $30 \%$ female participants. On the other hand, the female percentage was higher in the age group of over 60 years, with $25 \%$ female and $20 \%$ male belonging

\section{Gender Distribution}

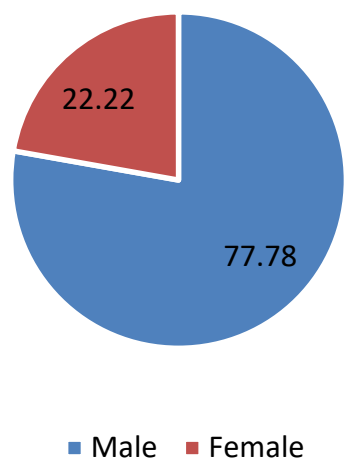

Figure 1. Gender distribution of the participants of case group $(\mathrm{n}=90)$. 
Table 1. Age distribution among the participants of case group $(n=90)$.

\begin{tabular}{cccccccc}
\hline \multirow{2}{*}{ Age (Yrs.) } & \multicolumn{2}{c}{ Male (M) } & \multicolumn{2}{c}{ Female (F) } & \multicolumn{2}{c}{ Total } & P value \\
\cline { 2 - 8 } & $\mathrm{n}$ & $\%$ & $\mathrm{n}$ & $\%$ & $\mathrm{n}$ & $\%$ & $(\mathrm{M}-\mathrm{F})$ \\
\hline $\mathbf{4 1 - 5 0}$ & 25 & 35.71 & 6 & 30 & 31 & 34.44 & \\
$51-60$ & 31 & 44.29 & 9 & 45 & 40 & 44.44 & \\
$>60$ & 14 & 20 & 5 & 25 & 19 & 21.11 & 0.242 \\
Total & 70 & 100 & 20 & 100 & 60 & 100 & \\
\hline
\end{tabular}

to this group. Looking at the total participants, the highest number of participants belonged to the age group of $51-60$ years.

In the case group, the serum Mean \pm SD cholesterol concentration in the age group of $41-50$ was $197.16 \pm 28.85 \mathrm{mg} / \mathrm{dL}$, in the age group $51-60$ it was 207.11 $\pm 18.65 \mathrm{mg} / \mathrm{dL}$, and in the patients older than 60 it was $263.91 \pm 23.73 \mathrm{mg} / \mathrm{dL}$. In the control group, it was $168.92 \pm 25.24 \mathrm{mg} / \mathrm{dL}, 118.75 \pm 17.15 \mathrm{mg} / \mathrm{dL}$, and $193.81 \pm 20.88 \mathrm{mg} / \mathrm{dL}$ respectively. Significance difference was observed between the serum cholesterol levels of both groups in all age range (Table 2).

In the case group, the Mean \pm SD distribution of triglyceride concentration in the age group of $41-50$ was $167.13 \pm 26.83 \mathrm{mg} / \mathrm{dL}$, in the age group of $51-60$ it was $210.71 \pm 42.17 \mathrm{mg} / \mathrm{dL}$, and in the participants aged over 60 , it was $152.56 \pm$ $34.64 \mathrm{mg} / \mathrm{dL}$. In the control group, it was $109.33 \pm 20.44 \mathrm{mg} / \mathrm{dL}, 125.64 \pm 31.71$ $\mathrm{mg} / \mathrm{dL}$, and $157.74 \pm 37.73 \mathrm{mg} / \mathrm{dL}$ respectively. $<150 \mathrm{mg} / \mathrm{dL}$ is considered nor$\mathrm{mal}, 150-199 \mathrm{mg} / \mathrm{dL}$ is considered borderline high, and $200-499 \mathrm{mg} / \mathrm{dL}$ is considered high levels of triglyceride concentration. All the age groups had higher-than-normal triglyceride concentrations in the case group. In the control group, only the oldest age group of $>60$ years had a higher-than-normal mean triglyceride concentration level (Table 3).

In the case group, the Mean \pm SD distribution of HDL concentration in the age group of $41-50$ was $40.52 \pm 5.77 \mathrm{mg} / \mathrm{dL}$. In the age group of $51-60$, it was $47.44 \pm 5.91 \mathrm{mg} / \mathrm{dL}$, and in the participants aged over 60 , it was $43.73 \pm 8.93$ $\mathrm{mg} / \mathrm{dL}$. In the control group, it was $50.71 \pm 6.39 \mathrm{mg} / \mathrm{dL}, 75.32 \pm 9.19 \mathrm{mg} / \mathrm{dL}$, and $86.74 \pm 10.48 \mathrm{mg} / \mathrm{dL}$ respectively. For men, less than $40 \mathrm{mg} / \mathrm{dL}$ is considered increased risk, and $40-50 \mathrm{mg} / \mathrm{dL}$ is considered average risk level, and $>60 \mathrm{mg} / \mathrm{dL}$ is considered low risk (Table 4). All the participants of the case group were in the average risk level, while the mean HDL concentration levels of the control group had the youngest age group of 41 - 50 years at less than average risk levels, and the remaining two age groups at low-risk levels. A significant difference was observed among the participants of the case and control group in all three age groups.

In the case group, the Mean \pm SD distribution of LDL concentration in the age group of $41-50$ was $99.88 \pm 20.73 \mathrm{mg} / \mathrm{dL}$. In the age group of $51-60$, it was $104.71 \pm 21.95 \mathrm{mg} / \mathrm{dL}$, and in the participants aged over 60 , it was $107.66 \pm 22.74$ $\mathrm{mg} / \mathrm{dL}$. In the control group, it was $75.87 \pm 12.56 \mathrm{mg} / \mathrm{dL}, 90.11 \pm 11.84 \mathrm{mg} / \mathrm{dL}$, and $97.82 \pm 15.77 \mathrm{mg} / \mathrm{dL}$ respectively. Basic LDL concentration standards are 
Table 2. Age-wise distribution of serum cholesterol concentration between the groups ( $\mathrm{n}$ $=131)$.

\begin{tabular}{cccc}
\hline Age $($ Yrs. $)$ & Case $(\mathrm{n}=\mathbf{9 0})$ & Control $(\mathrm{n}=41)$ & P value \\
\hline $\mathbf{4 1}-\mathbf{5 0}$ & $197.16 \pm 28.85$ & $168.92 \pm 25.24$ & $<0.0001$ \\
$\mathbf{5 1}-\mathbf{6 0}$ & $207.11 \pm 18.65$ & $118.75 \pm 17.15$ & $<0.0001$ \\
$>60$ & $263.91 \pm 23.73$ & $193.81 \pm 20.88$ & $<0.0001$ \\
\hline
\end{tabular}

Table 3. Age-wise distribution of triglyceride concentration between the groups $(\mathrm{n}=$ 131).

\begin{tabular}{cccc}
\hline Age $($ Yrs. $)$ & Case $(\mathrm{n}=\mathbf{9 0})$ & Control $(\mathrm{n}=41)$ & P value \\
\hline $\mathbf{4 1}-\mathbf{5 0}$ & $167.13 \pm 26.83$ & $109.33 \pm 20.44$ & $<0.0001$ \\
$\mathbf{5 1}-\mathbf{6 0}$ & $210.71 \pm 42.17$ & $125.64 \pm 31.71$ & $<0.0001$ \\
$>\mathbf{6 0}$ & $152.56 \pm 34.64$ & $157.74 \pm 37.73$ & 0.4783 \\
\hline
\end{tabular}

Table 4. Age-wise distribution of HDL concentration between the groups ( $\mathrm{n}=131)$.

\begin{tabular}{cccc}
\hline Age $($ Yrs. $)$ & Case $(\mathrm{n}=90)$ & Control $(\mathrm{n}=41)$ & P value \\
\hline $41-50$ & $40.52 \pm 5.77$ & $50.71 \pm 6.39$ & $<0.0001$ \\
$51-60$ & $47.44 \pm 5.91$ & $75.32 \pm 9.19$ & $<0.0001$ \\
$>60$ & $43.73 \pm 8.93$ & $86.74 \pm 10.48$ & $<0.0001$ \\
\hline
\end{tabular}

$<100 \mathrm{mg} / \mathrm{dL}$ as optimal, $100-129 \mathrm{mg} / \mathrm{dL}$ as above optimal, $130-159 \mathrm{mg} / \mathrm{dL}$ as borderline high and $160-189 \mathrm{mg} / \mathrm{dL}$ as high. While all three age groups of the control section had optimal LDL concentration levels, only the youngest age group of 41 - 50 years among the case group had optimal LDL levels, while the remaining age groups had above optimal LDL concentration levels (Table 5).

\section{Discussion}

Depending on the severity of coronary artery narrowing, the myocardial responses are divided into chest pain, acute myocardial infarction, sudden cardiac death, and chronic ischemic heart disease [14]. The most common risk factors of CHD are hypertension [15], smoking, obesity [16], diabetes, stress, gender, age, and dyslipidemia [17] [18]. There are also high levels of total cholesterol, Triacylglycerols (TAG), low-density lipoprotein cholesterol (LDL-C), and very-lowdensity lipoprotein (VLDL) and with low levels of High-density lipoprotein cholesterol (HDL-C) [19] which are considered as one of the most common modifiable risk factors for CHD [20]. The key role of cholesterol in $\mathrm{CHD}$ has given rise to the universally accepted cholesterol-diet-CHD hypothesis. According to this hypothesis, increased levels of plasma cholesterol concentrations increase the risk of CHD. This risk decreases with decreasing levels of plasma cholesterol concentrations. An Egyptian study also demonstrated that elevated plasma cholesterol levels increased the incidence of CHD. The Framingham study clearly demonstrated the association of elevated cholesterol with CHD [21]. Among 
Table 5. Age wise distribution of LDL concentration between the groups $(n=131)$.

\begin{tabular}{cccc}
\hline Age $($ Yrs. $)$ & Case $(\mathrm{n}=\mathbf{9 0})$ & Control $(\mathrm{n}=41)$ & P value \\
\hline $\mathbf{4 1}-\mathbf{5 0}$ & $99.88 \pm 20.73$ & $75.87 \pm 12.56$ & $<0.0001$ \\
$\mathbf{5 1}-\mathbf{6 0}$ & $104.71 \pm 21.95$ & $90.11 \pm 11.84$ & 0.0002 \\
$>\mathbf{6 0}$ & $107.66 \pm 22.74$ & $97.82 \pm 15.77$ & 0.515 \\
\hline
\end{tabular}

male participants of the Case Group 44.29\%, 35.71\%, and the rest $20 \%$ were from $51-60,41-50$, and $>60$ years' age group respectively. On the other hand, among the female participants of Case Group $45 \%, 30 \%$ and the rest $25 \%$ were from $51-60,41-50$, and $>60$ years' age group respectively. So middle age may be considered as a potential risk factor. Arteriosclerosis is not clinically evident until middle age or later when the arterial lesions precipitate the organ injury [22]. The incidence of myocardial infarction increases by five times between the ages ranging from $40-60$ [23]. In addition, men are much prone to develop atherosclerosis and its consequences compared to women [24]. Myocardial infarction, CHD, and atherosclerosis are uncommon in premenopausal women. It is theorized that the incidence of atherosclerosis-related disease increases due to a decrease in natural estrogen levels. Generally, the frequency of myocardial infarction in both sexes equalizes by the seventh to eighth decade of life. Dietary and lifestyle are also potential factors for CHD. Epidemiologic studies have linked the intake of high levels of dietary fat rich in cholesterol and saturated fats, with increased plasma cholesterol levels. Therefore, restriction of saturated fat and cholesterol is the cornerstone of dietary therapy to lower down the elevated blood cholesterol levels [25]. Despite the many works of literature on the relationship between lipid and lipoprotein particles to CHD incidence, there has been controversial evidence on the specific association of TAG with CHD. The Framingham study has demonstrated that TAGs are independently related in women of all ages, but the study showed missing statistical significance in the multivariate studies in men. According to two meta-analyses, TAGs were independent risk factors for CHD, even after adjustment with HDL-C, which is strongly and inversely correlated with TG [26]. In our study, in analyzing the age-wise distribution of triglyceride concentration between the groups, we found significant correlations between the Case and Control groups in 41 - 50 and 51 60 years age groups. In both age groups, the $\mathrm{P}$-value was found $<0.0001$. But in the participants above 60 years of age, we did not find any significant correlation and there the P-value was 0.478 . In analyzing the age-wise distribution of HDL concentration between the groups we found, significant correlations between the Case and Control groups in the participants of all age groups and the P-value was $<0.0001$ in every age group. On the other hand, in analyzing the age-wise distribution of LDL concentration between the groups, we found significant correlations between the Case and Control groups in $41-50$ and $51-60$ years age groups where the $\mathrm{P}$ values were found, $<0.0001$ and 0.0002 respectively. But in the participants aged above 60 , we did not find any significant correlation and 
there the P-value was 0.515. Clinical studies based on extensive literature support the inverse relationship between HDL-C levels and atherosclerosis. HDL enhances reverse cholesterol transport and has anti-oxidative, anti-inflammatory, antithrombotic, and vasoprotective effects [27]. Studies have also consistently demonstrated that HDL-C is inversely associated with the risk of CHD. Thus, an increase in HDL-C is linearly associated with a reduction in cardiovascular risk. In line with these findings, the present study demonstrated a significant decrease in the HDL-C levels in patients with CHD when compared to the control group patients [28]. The National Cholesterol Education Program (NCEP) recommends an LDL-C goal of $<100 \mathrm{mg} / \mathrm{dl}$ in patients with established CHD and in those who are CHD risk-equivalent. Aggressive LDL-C reduction is associated with less at hero sclerosis progression, lower rates of revascularization, and fewer ischemic events compared with moderate LDL-C reduction or conventional treatment.

\section{Conclusion}

In this study, it was found that the total cholesterol, triglycerides, and LDL cholesterol concentrations were significantly higher in coronary heart disease (CHD) patients. HDL concentrations were lower in patients with $\mathrm{CHD}$. These findings may be helpful in the treatment arena of CHD and similar further studies.

\section{Recommendations}

This was a single-centered study with a small-sized sample. So the findings of this study may not reflect the exact scenario of the whole country. For getting more specific information we would like to recommend conducting more studies in several places with a larger sized sample.

\section{Approval}

Collected from respective department.

\section{Conflicts of Interest}

The authors declare no conflicts of interest regarding the publication of this paper.

\section{References}

[1] D’Agostino, R.B., Russell, M.W., Huse, D.M., Ellison, R.C., Silbershatz, H., Wilson, P.W. and Hartz, S.C. (2000) Primary and Subsequent Coronary Risk Appraisal: New Results from the Framingham Study. American Heart Journal, 139, 272-281.

[2] Natarajan, P., Ray, K.K. and Cannon, C.P. (2010) High-Density Lipoprotein and Coronary Heart Disease: Current and Future Therapies. Journal of the American College of Cardiology, 55, 1283-1299.

[3] Adak, M. and Shivapuri, J.N. (2010) Serum Lipid and Lipoprotein Profile Abnormality in Predicting the Risk of Coronary Artery Disease in Non-Diabetic Patients Attending NMCTH, Birgunj. Nepal Medical College Journal, 12, 158-164. 
[4] Bonow, R.O., Carabello, B.A., Chatterjee, K., De Leon, A.C., Faxon, D.P., Freed, M.D., Gaasch, W.H., Lytle, B.W., Nishimura, R.A., O'Gara, P.T., O’Rourke, R.A., et al. (2006) ACC/AHA 2006 Guidelines for the Management of Patients with Valvular Heart Disease: A Report of the American College of Cardiology/American Heart Association Task Force on Practice Guidelines (Writing Committee to Revise the 1998 Guidelines for the Management of Patients with Valvular Heart Disease): Developed in Collaboration with the Society of Cardiovascular Anesthesiologists Endorsed by the Society for Cardiovascular Angiography and Interventions and the Society of Thoracic Surgeons. Journal of the American College of Cardiology, 114, e84-e231.

[5] Voight, B.F., Peloso, G.M., Orho-Melander, M., Frikke-Schmidt, R., Barbalic, M., Jensen, M.K., et al. (2012) Plasma HDL Cholesterol and Risk of Myocardial Infarction: A Mendelian Randomisation Study. The Lancet, 380, 572-580. https://doi.org/10.1016/S0140-6736(12)60312-2

[6] Ridker, P.M., Pare, G., Parker, A.N., Zee, R.Y., Miletich, J.P. and Chasman, D.I. (2009) Polymorphism in the CETP Gene Region, HDL Cholesterol, and Risk of Future Myocardial Infarction: Genomewide Analysis among 18245 Initially Healthy Women from the Women's Genome Health Study. Circulation: Cardiovascular Genetics, 2, 26-33.

[7] Brown, B.G., Zhao, X.Q., Chait, A., Fisher, L.D., Cheung, M.C., Morse, J.S., Dowdy, A.A., Marino, E.K., Bolson, E.L., Alaupovic, P. and Frohlich, J. (2001) Simvastatin and Niacin, Antioxidant Vitamins, or the Combination for the Prevention of Coronary Disease. New England Journal of Medicine, 345, 1583-1592. https://doi.org/10.1056/NEJMoa011090

[8] Maxfield, F.R. and Tabas, I. (2005) Role of Cholesterol and Lipid Organization in Disease. Nature, 438, 612-621. https://doi.org/10.1038/nature04399

[9] Underwood, J.C. and Cross, S.S. (2009) General and Systematic Pathology E-Book. Elsevier Health Sciences.

[10] Holick, M.F. (2007) Vitamin D Deficiency. New England Journal of Medicine, 357, 266-281. https://doi.org/10.1056/NEJMra070553

[11] Akanda, M.A., Ali, Z., Choudhury, K.N., Sayami, L.A., Huda, R.M., Hossain, S., Mohsin, M. and Ali, M.A. (2016) Study of Lipid Profile in Adult Population of Bangladesh. Cardiovascular Journal, 8, 128-134.

[12] Choudhury, K.N., Mainuddin, A.K., Wahiduzzaman, M. and Islam, S.M. (2014) Serum Lipid Profile and Its Association with Hypertension in Bangladesh. Vascular Health and Risk Management, 10, 327-332.

[13] Kumar, V., Abbas, A. and Aster, J. (2014) Robbins \& Cotran Pathologic Basis of Disease. 9th Edition, Elsevier, Singapore.

[14] Špinar, J. (2012) Hypertension and Ischemic Heart Disease. Cor et Vasa, 54, e433e438. https://doi.org/10.1016/j.crvasa.2012.11.002

[15] Paratz, E., Palmer, S. and Mariani, J. (2015) The Cardiac Complications of Obesity. Medicine Today, 16, 211-232.

[16] Sarwar, N., Danesh, J., Eiriksdottir, G., Sigurdsson, G., Wareham, N., Bingham, S., Boekholdt, S.M., Khaw, K.T. and Gudnason, V. (2006) Triglycerides and the Risk of Coronary Heart Disease: 10,158 Incident Cases among 262,525 Participants in 29 Western Prospective Studies. Circulation, 115, 450-458. https://doi.org/10.1161/CIRCULATIONAHA.106.637793

[17] Campos, W.D., Stabelini Neto, A., Bozza, R., Ulbrich, A.Z., Bertin, R.L., Mascarenhas, L.P., Silva, S.G. and Sasaki, J.E. (2010) Physical Activity, Lipid Consumption 
and Risk Factors for Atherosclerosis in Adolescents. Arquivos Brasileiros de Cardiologia, 94, 601-607. https://doi.org/10.1590/S0066-782X2010005000033

[18] Ahmed, S.M., Clasen, M.E. and Donnelly, J.F. (1998) Management of Dyslipidemia in Adults. American Family Physician, 57, 2192-2208.

[19] Assessment, R.E. (2009) Major Lipids, Apolipoproteins, and Risk of Vascular Disease. JAMA, 302, 1993-2000. https://doi.org/10.1001/jama.2009.1619

[20] Werner, M., Gabrielson, D.G. and Eastman, J. (1981) Ultramicro Determination of Serum Triglycerides by Bioluminescent Assay. Clinical Chemistry, 27, 268-271. https://doi.org/10.1093/clinchem/27.2.268

[21] Alarabawy, R.A., El Ahwal, H.M., Elwagih, M.M., Ismail, A. and Khattab, M.A. (2016) Use of Multi-Detector CT Angiography in Identification and Classification of Aortoiliac Diseases; Clinical and Surgical Application. The Egyptian Journal of Radiology and Nuclear Medicine, 47, 169-178. https://doi.org/10.1016/j.ejrnm.2015.09.005

[22] Bui, A.L., Horwich, T.B., and Fonarow, G.C. (2011) Epidemiology and Risk Profile of Heart Failure. Nature Reviews Cardiology, 8, 30-41.

https://doi.org/10.1038/nrcardio.2010.165

[23] Fuster, V., Kelly, B.B., Institute of Medicine (US) and Committee on Preventing the Global Epidemic of Cardiovascular Disease: Meeting the Challenges in Developing Countries (2010) Promoting Cardiovascular Health in the Developing World: A Critical Challenge to Achieve Global Health. National Academies Press, Washington DC.

[24] Yusuf, S., Hawken, S., Ôunpuu, S., Dans, T., Avezum, A., Lanas, F., McQueen, M., Budaj, A., Pais, P., Varigos, J. and Lisheng, L. (2004) Effect of Potentially Modifiable Risk Factors Associated with Myocardial Infarction in 52 Countries (the INTERHEART Study): Case-Control Study. The Lancet, 364, 937-952. https://doi.org/10.1016/S0140-6736(04)17018-9

[25] Wilson, P.W., Cupples, L.A. and Kannel, W.B. (1991) Is Hyperglycemia Associated with Cardiovascular Disease? The Framingham Study. American Heart Journal, 121, 586-590. https://doi.org/10.1016/0002-8703(91)90729-2

[26] Castelli, W.P., Anderson, K., Wilson, P.W. and Levy, D. (1992) Lipids and Risk of Coronary Heart Disease: The Framingham Study. Annals of Epidemiology, 2, 23-28. https://doi.org/10.1016/1047-2797(92)90033-M

[27] Gotto, A.M. (1991) Cholesterol Intake and Serum Cholesterol Level. New England Journal of Medicine, 324, 912-913.

[28] Panagiotakos, D.B. and Toutouzas, P.K. (2003) Importance of LDL/HDL Cholesterol Ratio as a Predictor for Coronary Heart Disease Events in Patients with Heterozygous Familial Hypercholesterolaemia: A 15-Year Follow-Up (1987-2002). Current Medical Research and Opinion, 19, 89-94. https://doi.org/10.1185/0300799039117034 